\title{
ANÁLISE FAUNÍSTICA E FLUTUAÇÃO POPULACIONAL DE MOSCAS-DAS- FRUTAS (DIPTERA: TEPHRITIDAE) EM POMARES COMERCIAIS DE GOIABA NA REGIÃO DO CARIRI CEARENSE
}

\author{
F.R. Azevedo ${ }^{1}$, J.A. Guimarães ${ }^{2}$, A.A.F. Simplício ${ }^{1}$, H.R. Santos ${ }^{1}$
}

${ }^{1}$ Universidade Federal do Ceará, Av. Tenente Raimundo Rocha, s/nº, CEP 63040-360, Juazeiro do Norte, CE, Brasil.E-mail: razevedo@ufc.br

\section{RESUMO}

Devido à importância das moscas-das-frutas como pragas da fruticultura, este trabalho teve como objetivos caracterizar as populações das moscas-das-frutas em pomares comerciais de goiaba na região do Cariri, Estado do Ceará, por meio de índices faunísticos e estudar a flutuação populacional dessas moscas ao longo do ano. Para isso, foram instaladas armadilhas McPhail nos Municípios de Barbalha, Crato e Juazeiro do Norte. As armadilhas foram examinadas semanalmente e as moscas capturadas foram triadas, conservadas em álcool a 70\% e identificadas. Constatou-se que Anastrepha zenildae (Wiedemann), A. sororcula Zucchi, A. fraterculus (Wiedemann), A. obliqua (Macquart) e Ceratitis capitata (Wiedemann) foram as moscas-das-frutas associadas à goiaba. Dessas, A. zenildae, A. sororcula e A. obliqua foram dominantes e constantes na região estudada, enquanto que $A$. fraterculus e $C$. capitata foram não-dominantes, mas também constantes. A. zenildae ocorreu em quase todos os meses do ano, exceto em outubro e dezembro de 2008, nos três pomares de goiaba do Cariri e com picos populacionais nos meses mais chuvosos e com temperaturas amenas.

PALAVRAS-CHAVE: Tephritidae, dinâmica populacional, Psidium guajava.

\section{ABASTRACT}

FAUNISTIC AND POPULATIONAL ANALYSIS OF FRUIT FLIES (DIPTERA: TEPHRITIDAE) INCOMMERCIAL GUAVA ORCHARDS IN THE CARIRI REGION (STATE OF CEARÁ), BRAZIL. Due to the importance of fruit-flies as pests in fruit growing, the present study was aimed to characterize the populations of fruit-flies in commercial guava orchards in the Cariri region (state of Ceará), Brazil, by means of faunistic indexes and to study their population fluctuation during the year. For this purpose, McPhail traps were installed in the counties Barbalha, Crato and Juazeiro do Norte. The traps were examined weekly and the captured flies were separated, preserved in $70 \%$ alcohol and identified. Anastrepha zenildae (Wiedemann), A. sororcula Zucchi, A. fraterculus (Wiedemann), A. obliqua (Macquart) and Ceratitis capitata (Wiedemann) were associated with guava fruits. Of them, A. zenildae, A. sororcula and A. obliqua were dominant and constant in the studied region, while $A$. fraterculus and $C$. capitata were non-dominant but constant. A. zenildae occurred in almost all months of the year, except October and December of 2008, with population peaks in the rainy season with its milder temperatures.

KEY WORDS: Tephritidae, population dynamics, Psidium guajava.

\section{INTRODUÇÃO}

A região do Cariri, localizada no sul do Estado do Ceará, tem se destacado pelogrande avançona exploração da fruticultura. A irrigação e as condições de solo e clima têm favorecido esse aumento da fruticultura. Com a ampliação das áreas cultivadas, há o aumento das pragas, inclusive as moscas-das-frutas. Esse fenômeno ocorre pelos processos naturais de dispersão, característico de cada espécie, ou também pelo transporte involuntário de frutos infestados de uma região para outra (MORGANTE, 1991).

As moscas-das-frutas são consideradas as principais pragas que assolam a fruticultura, em razão dos danos diretos que causam e da capacidade de adaptar-se em outras regiões, quando introduzidas. No Brasil, país de extensão continental, de clima tropical e biodiversidade exuberante, as dificuldades para se

${ }^{2}$ Embrapa Hortaliças - Laboratório de Entomologia, Brasília, DF, Brasil. 
estabelecer estratégias de controle dessas pragas são inúmeras, pois os problemas fitossanitários são distintos de uma região para outra.

A incidência das moscas-das-frutas é um sério problema na região do Cariri cearense, principalmente em goiabeiras (Psidium guajava L.), acarretando aumentos nos custos de produção, devido às aplicações de inseticidas e às perdas na produção. Além disso, os inseticidas usados no controle dessa praga causam impactos negativos sobre a entomofauna benéfica, além de serem prejudiciais à saúde humana e ao agroecossistema.

SOUTHWOOD (1995) ressalta a importância dos estudos básicos sobre a estrutura e o funcionamento das comunidades de insetos esugere modelos estatísticos para estudar a diversidade de espécies. No Brasil, são poucos os estudos de análise faunística de moscasdas-frutas, restringindo-se às regiões sul e sudeste (CANAl et al., 1998).

O monitoramento populacional das moscas-dasfrutas, realizado com o uso de armadilhas McPhail, permite verificar a flutuação populacional destes insetos e relacioná-la com os fatores abióticos, principalmente os relacionados ao clima, auxiliando na definição das épocas de maior ou menor probabilidade de infestações (Aluja, 1994; Araujo et al.; 2008; SALLES, 1995).

SALLES (2000) constatou que temperaturas abaixo de $10^{\circ} \mathrm{C}$ e superiores a $35^{\circ} \mathrm{C}$ influenciam a biologia das moscas-das-frutas, não havendo desenvolvimento de nenhumas das fases do ciclo de vida de Anastrepha fraterculus. Precipitação e umidade relativa também podem influenciar no desenvolvimento das moscas, já que a fase de pupa ocorre no solo e dessa forma, estes fatores podem ser cruciais para a emergência das moscas adultas (Aluja, 1994). Deve-se ressaltar que, além das variáveis climáticas, a flutuação populacional das moscas-das-frutas depende de uma série de fatores, comoa disponibilidadedefrutoshospedeiros,época do ano, hospedeiros alternativos, inimigos naturais, etc. Portanto,énecessário ter cautela noestabelecimentode determinadofator biótico ou abiótico comooúnicoouo principal responsável por picos populacionais das moscas em determinadas épocas do ano (SALLES, 1995; RonCHI-TELLES; SILVA, 2005; ArAujo et al., 2008).

A adoção do manejo integrado de pragas (MIP) na fruticultura tem incentivado o uso de outros métodos de controle, como os culturais, resistência de plantas, uso de produtos naturais e o controle biológico (CARVALHO, 1999).

No entanto, para o estabelecimento bem sucedido de estratégias de controle dessas pragas, énecessário conhecer a diversidade de espécies e sua abundância. Assim sendo, a presente pesquisa foi conduzida visando caracterizar as populações das moscas-dasfrutas por meio de índices faunísticos e estudar a flutuação populacional ao longo do ano em pomares comerciais de goiaba do Cariri Cearense.

\section{MATERIALEMÉTODOS}

\section{Áreas de estudo}

As moscas-das-frutas foram capturadas em três pomares comerciais de goiaba (Psidium guajava L.) cv. Paluma, sem nenhum tipo de tratamento fitossanitário, nos municípios de Barbalha, CE (Latitude $7^{\circ} 17^{\prime} 32,4^{\prime \prime}$ S e Longitude $\left.39^{\circ} 20^{\prime} 14,19^{\prime \prime O}\right)($ de maio de 2007 a abril de 2008), apresentando nas proximidades culturas de graviola e cana-de-açúcar; Crato, CE (Latitude $7^{\circ} 13^{\prime}$ 25,1"Se Longitude $39^{\circ}$ 23' 29,63"O)(de agosto de 2007 a julho de 2008), com a presença de pomares de manga, de laranja e plantas de cajá e Juazeiro do Norte, CE (Latitude $7^{\circ} 16^{\prime} 14^{\prime \prime}$ Se Longitude $39^{\circ} 21^{\prime} 30^{\prime \prime O}$ ) (de julho de 2007 a junho de 2008) em uma área cercada com diversas culturas de importância agrícola.

\section{Capturas das moscas-das-frutas}

Armadilhas plásticas do tipo McPhail contendo proteína hidrolizada de milho a $5 \%$ foram instaladas nos pomares comerciais de goiaba para capturar os adultos das moscas-das-frutas.

Em cada pomar de goiaba foram instaladas quatro armadilhas nas plantas com frutos, independente do porte. As armadilhas foram posicionadas em local sombreado, distantes 100 metros uma das outras em uma altura de aproximadamente 1,5 metros na copa das árvores. Em cada armadilha colocou-se cerca de $400 \mathrm{~mL}$ da solução do atrativo.

Semanalmente, as armadilhas foram examinadase as moscas atraídas eram coletadas, utilizando-se uma peneira de malha fina. Os insetos capturados foram acondicionados em recipientes plásticos de $100 \mathrm{~mL}$ contendo álcool a 70\%, devidamente etiquetados. Em seguida, esse material foi levado ao laboratório de Entomologia da Universidade Federal do Ceará Campus Cariri, para triagem e contagem das moscas.

As armadilhas permaneceram instaladas no pomar durante todo o período de estudo. Apenas o atrativo alimentar era reposto uma vez por semana, durante a coleta das moscas. Os espécimes obtidos foram quantificados e preservados em frascos de vidro contendo álcool a 70\% para a identificação das espécies de moscas-das-frutas.

\section{Identificação taxonômica}

As moscas foram identificadas como Ceratitis capitata (Wiedemann) pelo diagnóstico das caracte- 
rísticas morfológicas das asas, cerdas pós-oculares e escutelares (FoOTE, 1980).

A identificação das espécies de Anastrepha foi baseada nos caracteres morfológicos das fêmeas, usando o padrão alar, torácico, mediotergito (metanoto), subescutelo (pós-escutelo) e pelo exame do acúleo (ZuCCHI, 2000).

\section{Análise faunística}

Cada pomar foi considerado uma comunidade com características próprias, determinadas por meio dos índices faunísticos propostos por SILVEIRA NeTOet al. (1976) e SouthwoOd (1995), tais como:

- Frequência: pi = ni/N, onde ni: número de indivíduos da espécie i e N: total de indivíduos da amostra.

É a proporção de indivíduos de uma espécie em relação ao total de indivíduos da amostra.

- Constância: Porcentagem de amostras em que uma determinada espécie esteve presente.

$\mathrm{C}=\mathrm{p} .100 / \mathrm{N}$, onde p: número de amostras com a espéciee N: número total de amostras tomadas. Classificação das espécies quanto à constância:

- Espécie constante: presente em mais de 50\% das amostras.

- Espécie acessória: Presente em 25-50\% das amostras.

-Espécieacidental:Presenteem menos de 25\% das amostras.

- Riqueza (S): Número total de espécies observadas na comunidade.

- Número de espécies dominantes: Uma espécieé considerada dominante quando apresenta frequência superior a 1/S, ondeSé o número total de espécies na comunidade.

\section{Flutuação populacional}

Foram analisadas as flutuações populacionais do total de moscas capturadas nas armadilhas instaladas nos pomares. A variação sazonal das populações das moscas foi baseada no número total de fêmeas capturadas mensalmente. Esse valor foi obtido somando-se os números dos adultos capturados em todas as armadilhas nas quatro semanas de cada mês.

Os dados de pluviosidade relativos ao período do experimento foram obtidos na Estação Meteorológica da Fundação Meteorológica do Ceará (FUNCEME) localizada no Município de Fortaleza.

\section{RESULTADOSEDISCUSSÃO}

\section{Análise faunística}

No Município de Barbalha foram coletadas 83 fêmeas de três espécies (Anastrepha zenildae (Wiedemann), A.fraterculus (Wiedemann)e A. sororcula Zucchi de tefritídeos nas armadilhas (Tabela 1). Essas espécies de Anastrepha são consideradas, segundo ZuCCHI (2000), particularmente importantes do ponto de vista econômico para a fruticultura brasileira. MOURA; Moura (2006) também verificaram baixa riqueza de espécies de moscas-das-frutas em goiabeiras de Fortaleza, tendo encontrado também três espécies atacando essa cultura.

Das moscas coletadas em Barbalha, A. zenildae foi a mais frequente, representando $62,7 \%$ da população total. Essa espécie foi dominante e também a mais constante na população, apresentando $100 \%$ de constância. De acordo com CANAL et al. (1998), A. zenildae é considerada praga-chave para a cultura da goiaba no norte do Estado de Minas Gerais. SAntos et al. (1998) também constataram essa espécie em Mossoró, $\mathrm{RN}$, e áreas adjacentes, atacando goiabeiras. No entanto, em pomar urbano de goiaba em Fortaleza, Moura; Moura (2006) constataram que essa espécie não era dominante. No Estado de São Paulo, RAGA et al. (2005) já verificaram dominância de $A$. fraterculus com $76,62 \%$ das fêmeas coletadas em goiabas, enquanto que $A$. zenildae atingiu apenas $0,49 \%$ da população. As demais espécies coletadas em Barbalha como $A$. fraterculus e $A$. sororcula foram consideradas espécies não dominantes e acessórias.

Tabela 1 - Índices faunísticos de moscas-das-frutas (fêmeas) coletadas em um pomar comercial de goiaba em Barbalha, CE, durante o período de maio de 2007 a abril de 2008.

\begin{tabular}{lcccc}
\hline Espécies (riqueza) & $\mathrm{n}_{\mathrm{i}}$ & Frequência (\%) & Dominância & Constância (\%) \\
\hline A. zenildae (Wiedemann) & 52 & 62,7 & $\mathrm{~d}$ & $100,0 \mathrm{c}$ \\
A. sororcula Zucchi & 19 & 22,9 & nd & $41,7 \mathrm{ac}$ \\
A. fraterculus (Wiedemann) & 12 & 14,5 & nd & 50,0 ac \\
\hline Total & 83 & - & - & -
\end{tabular}

$\mathrm{d}$ = dominante; nd = não dominante.

$\mathrm{c}=$ espécie constante; $\mathrm{ac}=$ espécie acessória. 
No Município do Crato foram coletadas, ao todo, 300 fêmeas de seis espécies (A. zenildae, A. obliqua (Macquart), A. fraterculus, A. sororcula, Ceratitis capitata (Wiedemann) e A. amita Zucchi de tefritídeos nas armadilhas (Tabela 2).

A. zenildae foi a espécie mais frequente no pomar, representando $44 \%$ da população total. Foi também a mais constante, com $83,3 \%$ de constância. Essa espécie foi dominante, assim como $A$. obliqua na população estudada. A espécie $A$. sororcula apresentou uma constância de $66,7 \%$ (Tabela 2), porém, foi pouco frequente na comunidade. Devido à baixa constância de C. capitata (41,7\%) e A. amita (16,7\%), elas foram consideradas acessórias e acidentais, respectivamente.

A maior frequência de A. obliqua, quando comparada com as espécies de $A$. fraterculus, $A$. sororcula e $C$. capitata foi provavelmente devido a sua preferência por Anacardiáceas, algumas das quais presentes próximas ao pomar de goiaba do Crato. Esse mesmo comportamento de A. obliqua foi observado por DUTRA et al. (2009) em pomares de goiaba no Município de Una na Bahia.

Obaixoíndice de constância obtido para C. capitata (41,7\%) (Tabela 2) indica que a ocorrência dessa espécie no pomar de goiaba no Crato foi acessória, provavelmente pela preferência por outra planta hospedeira na vegetação adjacente ao pomar, já que no Crato existiam outros frutos hospedeiros como laranjas, pois, em levantamentos realizados por meio deinspeções diretas e por armadilhas d'água, Jackson e McPhail, em seis grandes áreas do interior do Estado do Ceará, SALES; GONÇALVES (2000) também evidenciaram a ocorrência de $A$. zenildae e $A$. sororcula em goiabeiras, entretanto, $C$. capitata foi constatada apenas nas culturas do cafeeiro e da tangerineira.

Em Juazeiro do Norte foram coletadas 1.722 fêmeas detefritídeos deseisespécies (A.zenildae, A. sororcula, A. obliqua, A. fraterculus, C. capitata e A. antunesi Lima) nas armadilhas (Tabela 3), apresentando a mesma riqueza de espécies do Crato.

A. zenildae também foi a espécie mais frequente $(45,7 \%)$ nesta comunidade, com frequência similar a obtida no Crato (Tabela 3). Essa espécie foi dominante, assim como $A$. sororcula, ambas com $100 \%$ de constância nas amostras coletadas. Já $A$. fraterculus e $A$. sororcula apresentaram menor frequência. De acordo com Malavasi et al.(2000), na região Nordeste do Brasil, A. fraterculus predomina no litoral que é mais úmidoe $A$. zenildae $A$. sororcula ocorrem predominantemente nas áreas quentes como é caso da região do Cariri Cearense. Essas mesmas espécies também foram dominantes em pomares de goiaba do nordeste mineiro (CORSATO, 2004). Resultados semelhantes foram obtidos por ARAUjo et al. (2006) em Mossoró, RN, e por ARAujo et al. (2008) em Russas, CE, demonstrando que essas moscas apresentam ampla distribuição geográfica no Semi-Árido Nordestino. No Rio de Janeiro predomina a espécie $A$. fraterculus em pomares de goiabas de Italva, Itaperuna (FERRARA et al., 2005), Cambuci e Itaocara (AguiAR-Menezes et al., 2008). A. obliqua e C. capitata foram constantes, ambas com $91,7 \%$ de constância, enquanto que $A$. fraterculus foi considerada acessória com $50 \%$ de constância e $A$. antunesi acidental, com 16,7\% (Tabela 3).

Portanto, com base nos resultados obtidos nos três municípios estudados, foi constatado que $A$. zenildae, A. sororcula e $A$. obliqua foram dominantes entre as sete espécies encontradas. Tal fato pode ser atribuído a homogeneidade dos pomares comerciais de goiaba, ondenormalmente essas espécies constituem-secomo pragas-chave(CANALet al.,1998). As outras espécies de moscas-das-frutas foram encontradas nesses pomares, possivelmente, em razão da existência de agroecossistemas adjacentes compostos de outras fruteiras hospedeiras preferenciais e/ou vegetação nativa do entorno, contribuindopara a ocorrência deespécies acessóriase/ouacidentais nas amostras coletadas.

Tabela 2 - Índices faunísticos de moscas-das-frutas (fêmeas) coletadas em um pomar comercial de goiaba em Crato, CE, durante o período de agosto de 2007 a julho de 2008.

\begin{tabular}{lrccc}
\hline Espécies (riqueza) & \multicolumn{1}{c}{$\mathrm{n}_{\mathrm{i}}$} & Frequência (\%) & Dominância & Constância (\%) \\
\hline A. zenildae (Wiedemann) & 132 & 44,0 & $\mathrm{~d}$ & $83,3 \mathrm{c}$ \\
A. obliqua (Macquart) & 56 & 18,7 & $\mathrm{~d}$ & $66,7 \mathrm{c}$ \\
A. fraterculus (Wiedemann) & 46 & 15,3 & nd & $58,3 \mathrm{c}$ \\
A. sororcula Zucchi & 45 & 15,0 & nd & $66,7 \mathrm{c}$ \\
C. capitata (Wiedemann) & 17 & 5,7 & nd & 41,7 ac \\
A. amita Zucchi & 4 & 1,3 & & \\
\hline Total & 300 & & & 16,7 acd \\
\hline
\end{tabular}

$\mathrm{d}$ = dominante; nd = não dominante.

$\mathrm{c}=$ espécie constante; $\mathrm{ac}=$ espécie acessória; acd $=$ espécie acidental 
Tabela 3 - Índices faunísticos de moscas-das-frutas (fêmeas) coletadas em um pomar comercial de goiaba em Juazeiro do Norte, durante o período de julho de 2007 a junho de 2008.

\begin{tabular}{lcccc}
\hline Espécies (riqueza) & $\mathrm{n}_{\mathrm{i}}$ & Frequência (\%) & Dominância & Constância (\%) \\
\hline A. zenildae (Wiedemann) & 787 & 45,7 & $\mathrm{~d}$ & $100,0 \mathrm{c}$ \\
A. sororcula Zucchi & 365 & 21,2 & $\mathrm{~d}$ & $100,0 \mathrm{c}$ \\
C. capitata (Wiedemann) & 260 & 15,1 & nd & $91,7 \mathrm{c}$ \\
A. obliqua (Macquart) & 208 & 12,1 & nd & $91,7 \mathrm{c}$ \\
A. fraterculus (Wiedemann) & 97 & 5,6 & nd & 50,0 ac \\
A. antunesi Lima & 5 & 0,3 & & 16,7 acd \\
\hline Total & 1.722 & & & \\
\hline
\end{tabular}

$\mathrm{d}=$ dominante; nd = não dominante.

c = espécie constante; ac = espécie acessória; acd = espécie acidental.

A dominância de poucas espécies de tefritídeos também foi verificada por outros pesquisadores em trabalhos similares realizados no Brasil (KOVALESKI, 1997; Veloso, 1997; Garcia; CorseuIL, 1998; Uramoto et al., 2003; URAMOTO et al., 2004). Essas constatações vêm confirmar a importância que as espécies de $A$. zenildae, A. sororcula, C.capitata, A.oblíqua e A.fraterculus têm para a cultura da goiaba nordestina. Segundo SouzA-Filhoetal. (2007), A fraterculus, A. sororcula e $A$. zenildae são espécies que atualmente utilizam a goiaba como hospedeira preferencial no Estado da Bahia que também é no Nordeste.

\section{Flutuação populacional das moscas-das-frutas}

Em Barbalha, as densidades populacionais das espécies de Anastrepha foram baixas ao longo dos doze meses de estudo, não chegando a atingir dez indivíduos mensais, com apenas $A$. zenildae alcançando dezesseis indivíduos no mês de novembro de 2007 (Fig. 1). A. sororcula atingiu a maior densidade populacional no mês de dezembro desse mesmo ano, com nove indivíduos capturados, enquanto que $A$. fraterculus não passou dos três indivíduos durante o período de avaliação. Nos meses de novembro e dezembro de 2007 foram registrados 51,8 e 196,5 mm de chuvas, respectivamente (FunCEME, 2009). No entanto, não choveu nos meses de junho a outubro. Esse fato pode ter contribuído para a redução da população das moscas. Nos meses de janeiro a abril de 2008 ocorreu aumento na precipitação, com pico no mês de março (560,8 mm), mas a população permaneceu abaixo de quatro indivíduos no pomar.

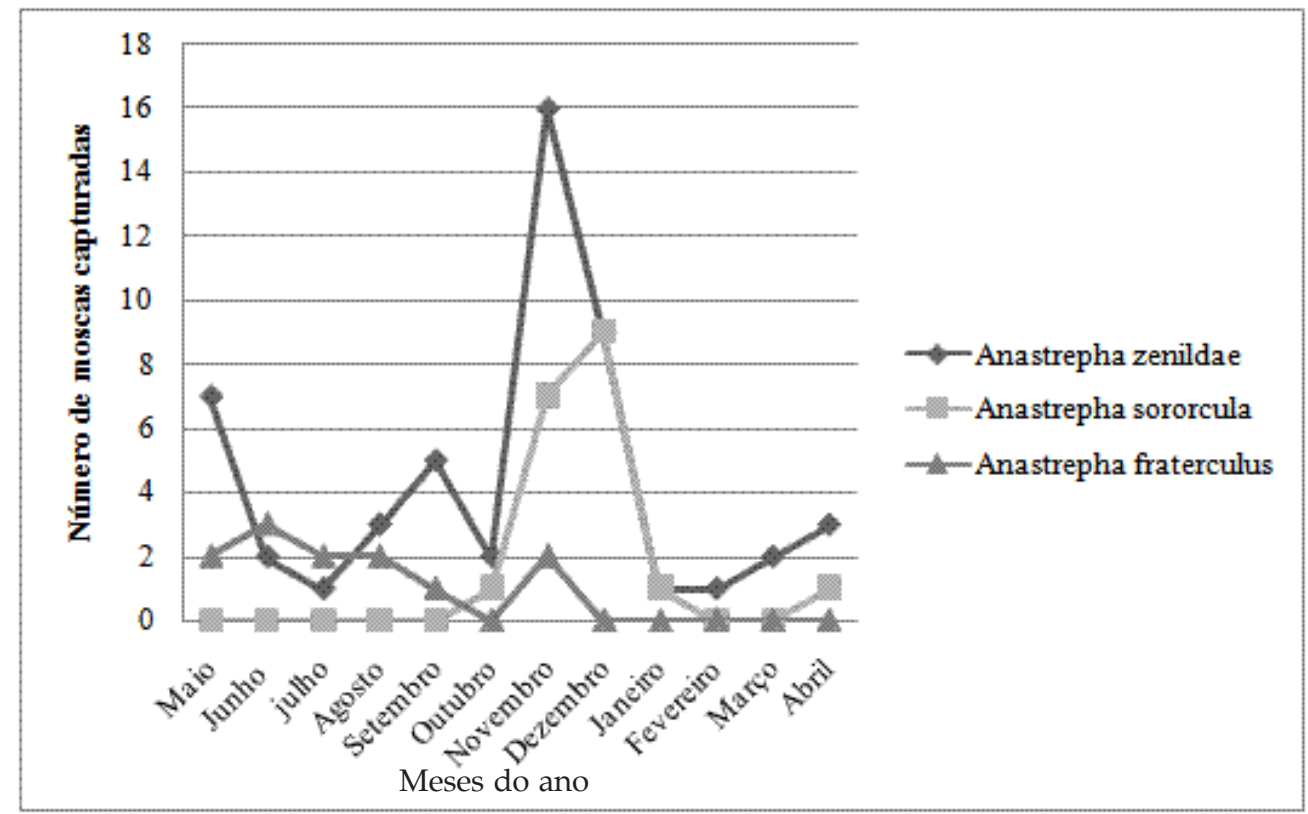

Fig. 1 - Flutuação populacional de espécies de moscas-das-frutas coletadas em pomar comercial de goiaba. Barbalha, CE (maio de 2007 a abril de 2008). 
Essas baixas densidades das moscas capturadas no pomar em estudo também podem estar relacionadas à eliminação de frutos de goiaba caídos no solo, pois essa prática cultural é intensamente realizada nessa área, já que a pesquisa foi conduzida na Estação deFruticultura do CENTEC, queé uma instituição de ensino e pesquisa, fator esse que pode ter impedido o desenvolvimento e a proliferação desses tefritídeos. URAMOTO (2002) recomenda a catação de frutos caídos ao solo em áreas com fruteiras para eliminar sítios de oviposição para as moscas-das-frutas, reduzindo assim sua população. Próximo desse pomar existia culturas não preferidas pelas moscas como graviola e cana-de-açúcar, fator que também pode ter contribuído para não haver migrações de outras áreas para o pomar avaliado.

No Crato, as densidades populacionais das espécies de moscas-das-frutas foram maiores que as de Barbalha, constatando-se os maiores picos no mês de maio (Fig. 2), apesar de não ter havido disponibilidade de frutos hospedeiros neste período. No entanto, o período chuvoso ofereceu condições favoráveis para os insetos sobreviverem, pois foi registrada nesse mês uma precipitação de 251,7 mm (FunCEME, 2009). A. zenildae, mais uma vez, se destacou das demais, atingindo uma população com oitenta e dois indivíduos (Fig. 2), seguida por A. sororcula com vinte e nove e $A$. fraterculus com vinte um. As demais espécies apresentaram populações muito baixas nesse mês, variando de zero a dois indivíduos.

Verificou-se que, à medida que houve aumento gradativo na precipitação, ocorreu um aumento também gradativo no número de moscas coletadas. Diante dos resultados obtidos, pode-se sugerir que a ocorrência dessas espécies de tefritídeos para as condições do Crato encontra-se, em parte, relacionada à precipitação. Tal fato foi observado também por BATEMAN (1972), que verificou que a abundância de moscas-das-frutas no campo pode ser influenciada pela precipitação. Aluja (1994), ao realizar estudos em pomares comerciais, observou que as flutuações populacionais de adultos de tefritídeos estão diretamente relacionadas à disponibilidade de frutos hospedeiros e condições meteorológicas, como as chuvas.

Da mesma forma que ocorreu com as espécies do gênero Anastrepha, acredita-se que as condições climáticas, principalmente a precipitação, tenham influenciado a ocorrência e flutuação populacional de C. capitata na goiabeira, para as condições do Crato. No entanto, a presença de plantas de café nas proximidades da área provavelmente influenciou na baixa captura dessa espécie já que a ela tem preferência por essa cultura. Em regiões tropicais $C$. capitata ocorre mais frequentemente em hospedei- ros introduzidos (MALAVASI et al., 1980), como o cafeeiro.

Em Juazeiro do Norte, as densidades populacionais das espécies de Anastrepha foram altas em todos os meses avaliados (Fig. 3). A. zenildae apresentou os maiores picos populacionais nos meses de novembro de 2007, com cento e sessenta e seis indivíduos e no mês de março de 2008, com cento e sessenta e dois indivíduos. A. sororcula apresentou os maiores picos nos meses de novembro edezembro de2007, com setenta e oito enoventa eum indivíduos, respectivamente. Enquanto que $A$. oblíqua teve sua maior população no mês de março de 2008, com sessenta indivíduos. Já em Monte Alegre doSul, SP, $A$. fraterculus teve seu pico populacional em março, quando todos os frutos ficam maduros, ocorrendo outro pico em agosto e depois em setembro (SOUZA-FILHO $\boldsymbol{e} t$ al., 2009). Em São Paulo, SP, o pico populacionalde $A$. fraterculus ocorre somente no final da safra da goiaba (Malavasi; Morgante, 1981). Em 2007, a maior precipitação ocorreu no mês de dezembro (128 mm), enquanto que, em 2008, observou-se maior precipitação em março (528 mm)(FUNCEME, 2009). Esse fator contribuiu muito para o aumento das populações de Anastrepha. Porém, MourA; Moura (2006) verificaram que a ocorrência de espécies desse gênero na cultura da goiaba em uma área urbana de Fortaleza restringiu-se aos meses de março, abril e maio de 2000, não sendo registrada a ocorrência de um único indivíduo infestando a goiabeira nos demais meses. A presença de moscas-das-frutas nas áreas rurais e urbanas ocorre em razão da concentração dos seus hospedeiros favoritos em uma ou outra área (AlvARENGA et al., 2009).

C. capitata apresentou maior densidade populacional no mês de janeiro, com cento e sete indivíduos capturados (Fig. 3), porém, a população decresceu nos meses seguintes, sendo detectado apenas um indivíduo no mês de julho. Resultados semelhantes foram obtidos por MOURA; MOURA (2006) que verificaram que essa espécie atingiu seu maior pico populacional no mês de janeiro, quando foram coletados duzentos e oitenta e sete indivíduos, representando cerca de $35 \%$ do total de C. capitata coletado. Esses autores também não detectaram a presença dessa espécie no mês de agosto de 2000, em Fortaleza, na cultura da goiaba devido à baixa disponibilidade de frutos hospedeiros, limitandose, assim, a existência de sítios de oviposição. Isso também ocorreu na presente pesquisa. Deve-se ressaltar, porém, que neste trabalho não foi avaliada a influência dos fatores bióticos, como parasitismo, predação e competição que, juntamente com os fatores abióticos, são responsáveis pela regulação da flutuação populacional das pragas ao longo dos meses do ano. 


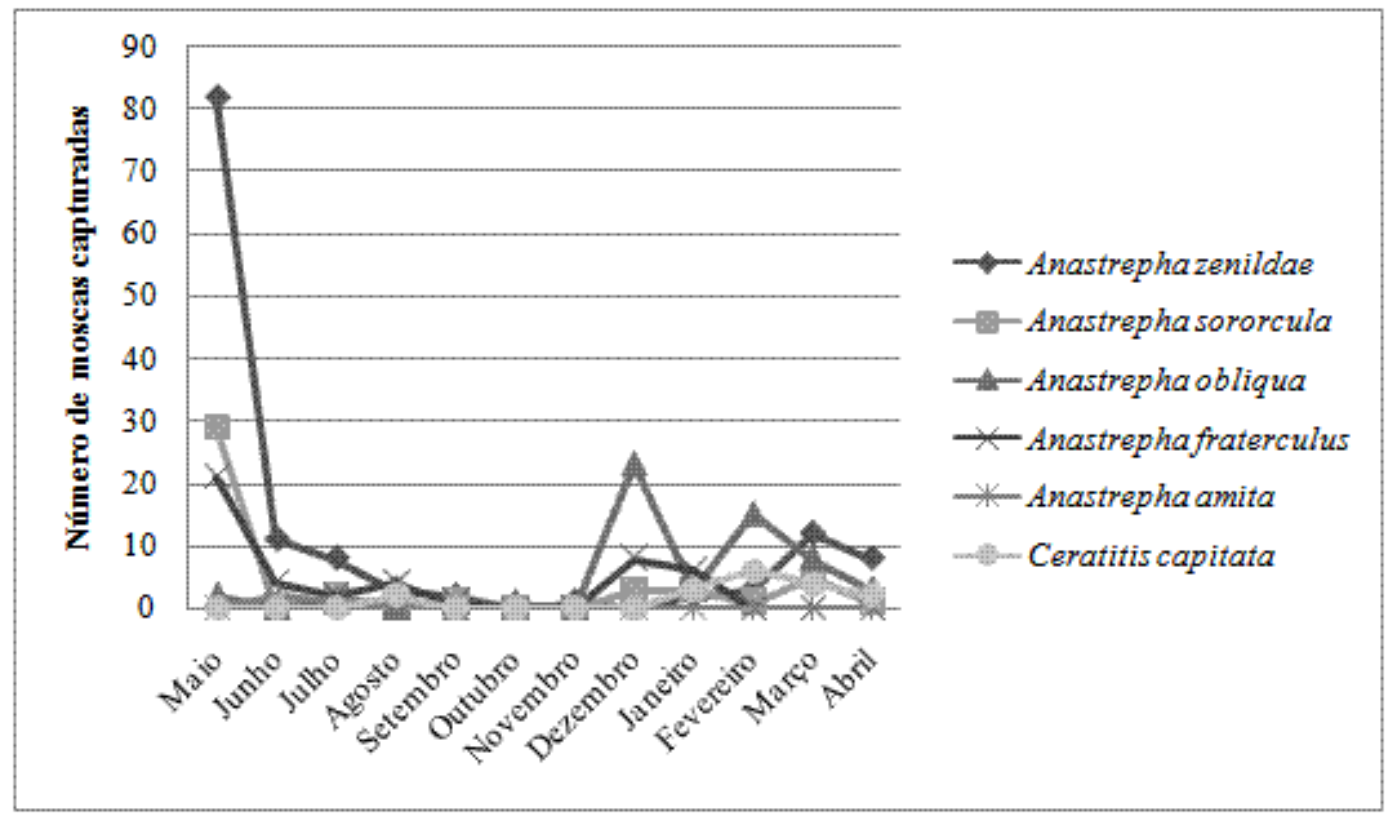

Fig. 2 - Flutuação populacional de espécies de moscas-das-frutas coletadas em pomar comercial de goiaba. Crato, CE (maio de 2007 a abril de 2008).

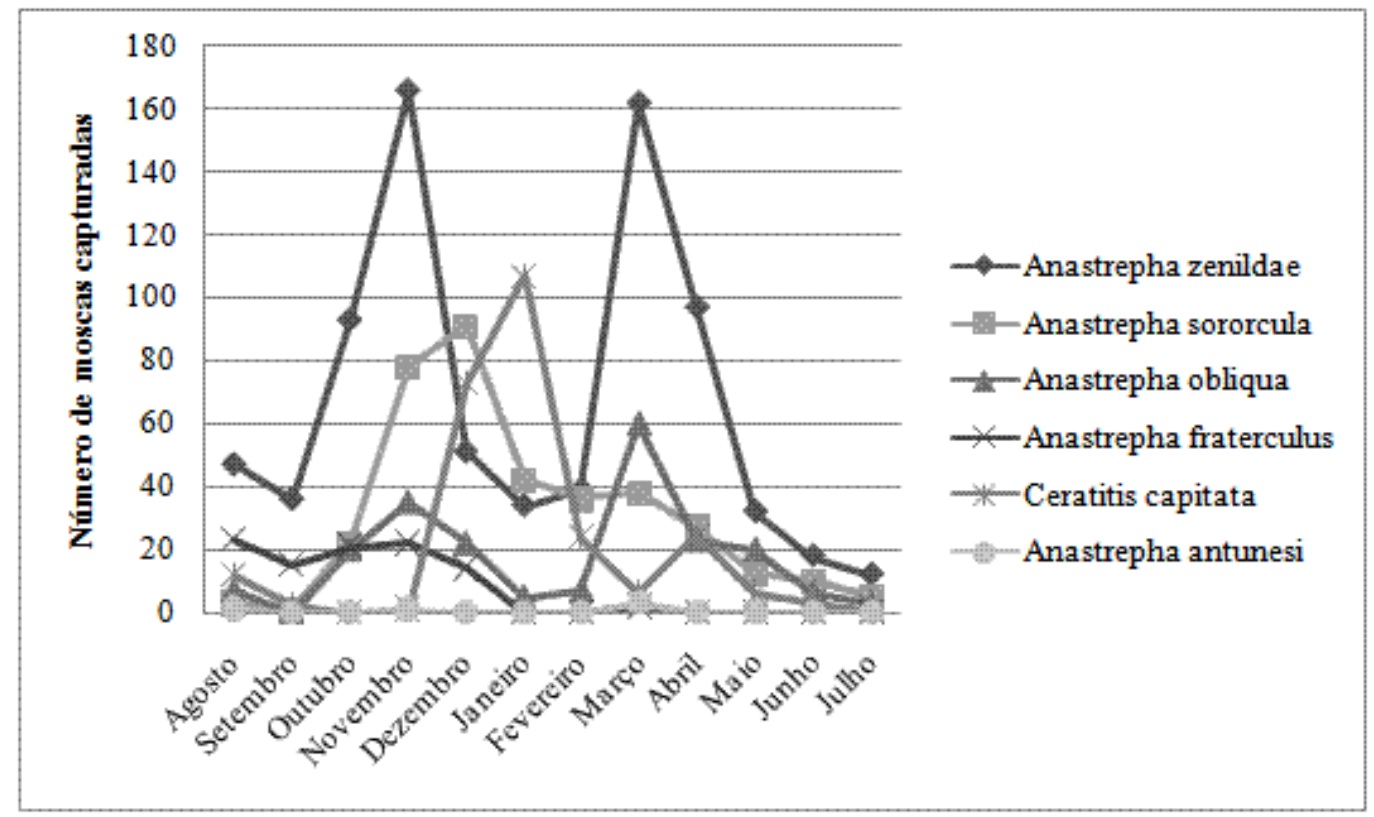

Fig. 3 - Flutuação populacional de espécies de moscas-das-frutas coletadas em pomar comercial de goiaba. Juazeiro do Norte, CE (agosto de 2007 a julho de 2008).

\section{CONCLUSÕES}

1. A. zenildae, A. sororcula, A. fraterculus, $A$. obliqua e C. capitata são as espécies de moscasdas-frutas associadas à goiabeira no Cariri Cearense;

2. A. zenildae, A. sororcula e A. obliqua são espécies dominantes e constantes na região estudada, enquanto que $A$. fraterculus e C. capitata são espécies não-dominantes embora sejam também constantes;

3. A. zenildae é o tefritídeo mais frequente nos pomares de goiaba na região do Cariri;

4. A. zenildae ocorre em quase todos os meses do ano, exceto em outubro e dezembro de 2008, nos três pomares de goiaba do Cariri; 
5. O período de maior incidência de moscas-dasfrutas em pomares de goiaba no Cariri é o chuvoso e com temperaturas amenas.

\section{REFERÊNCIAS}

AGUIAR-MENEZES, E.L.;SOUZA, S.A.S.; LIMA FILHO, M.; BARROS, H.C.; FERRARA, F.A.A.; MENEZES, E.B. Análise faunística de moscas-das-frutas (Diptera: Tephritidae) nas regiões Norte e Noroeste do estado do Rio de Janeiro. Neotropical Entomology, v.7, p.8-14, 2008.

ALUJA, M. Bionomics and management of Anastrepha. Annual Review of Entomology, v.39, p.155-178, 1994.

ALVARENGA, C.D.; MATRANGOLO, C.A.R.; LOPES, G.N.; SILVA, M.A.; LOPES, E.N.; ALVES, D.A.; NASCIMENTO, A.S.; ZUCCHI, R.A. Moscas-das-frutas (Diptera: Tephritidae) e seus parasitóides em plantas hospedeiras de três municípios do Norte do estado de Minas Gerais. Arquivos do Instituto Biológico, São Paulo, v.76, n.2, p.195-204, 2009. Disponível em: < http:/ / www.biologico.sp.gov.br/docs/arq/v76_2/ alvarenga.pdf $>$. Acesso em: 6 jul. 2009.

ARAUJO, E.L.; MEDEIROS, M.K.M.;SILVA, V.E.; ZUCCHI, R.A. Moscas-das-frutas (Diptera: Tephritidae) no semi-árido do Rio Grande do Norte: plantas hospedeiras e índices de infestação. Neotropical Entomology, v.34, n.6, p.889-894, 2006.

ARAUJO, E.L.; SILVA, R.K.B.; GUIMARÃES, J.A.; SILVA, J.G.; BITTENCOURT, M.A.L. Levantamento e flutuação populacional de moscas-das-frutas (Diptera: Tephritidae) em goiaba Psidium guajava L., no município de Russas (CE). Caatinga, v.21, n.1, p.138-146, 2008.

BATEMAN, M.A. The ecology of fruit flies. Annual Review of Entomology, v.17, p.493-517, 1972.

CANAL, N.A.; ALVARENGA, C.D.; ZUCCHI, R.A. Análise faunística de espécies de moscas-das-frutas (Diptera: Tephritidae) em Minas Gerais. Scientia Agricola, v.55, n.1, p.15-24, 1998.

CARVALHO, R.S.; NASCIMENTO, A.S.; MATRANGOLO, W.J.R. Inseto exótico controla moscas-das-frutas. A lavoura, v.3, p.40-43, 1999.

CORSATO, C.D.A. Moscas-das-frutas (Diptera: Tephritidae) em pomares de goiaba no norte de Minas Gerais: Biodiversidade, parasitóides e controle biológico. 2004. 95p. Tese (Doutorado) - Escola Superior de Agricultura "Luiz de Queiroz", Universidade de São Paulo, Piracicaba, 2004.

DUTRA, V.S.; SANTOS, M.S.; SOUZA FILHO, Z.A.; ARAÚJO, E.L.; SILVA, J.G. Faunistic analysis of Anastrepha spp. (Diptera: Tephritidae) on a guava orchard under organic management in the municipality of Una, Bahia, Brasil. Neotropical Entomology, v.38, n.1, p.133-138, 2009.

FERRARA, F.A.A.; AGUIAR-MENEZES, E.L.; URAMOTO, K.; MARCO JUNIOR, P. SOUZA, S.A.S. CASSINO, P.C.R. Análise faunística de moscas-dasfrutas (Diptera: Tephritidae) da região noroeste do Estado do Rio de Janeiro. Neotropical Entomology, v.34, p.183-190, 2005.

FOOTE, R.H. Fruit fly genera South of the United States. Washington: Science and Education Administration, USDA, 1980. 79p. (Technical Bulletin 1600).

FUNCEME - Fundação Cearense de Meteorologia e Recursos Hídricos, 2009. Disponível em: <http:/ / www.funceme.br>. Acesso em: 13 fev. 2009.

GARCIA, F.R.M.; CORSEUIL, E. Flutuação populacional de Anastrepha fraterculus (Wiedemann) e Ceratitis capitata (Wiedemann) (Diptera, Tephritidae) em pomares de pessegueiro em Porto Alegre, Rio Grande do Sul. Revista Brasileira de Zoologia, v.15, n.1, p.153-158, 1998.

KOVALESKI, A. Processos adaptativos na colonização da maçã (Malus domestica Borkh.) por Anastrepha fraterculus (Wied.) (Diptera: Tephritidae) na região de Vacaria, RS. 1997. 122p. Tese (Doutorado) - Instituto de Biociências, Universidade de São Paulo, São Paulo, 1997.

MALAVASI, A.; MORGANTE, J.S. Adult and larval population fluctuation of Anastrepha fraterculus and its relationship to host availability. Environment Entomology, v.10, n.3, p.275-278, 1981.

MALAVASI, A.; MORGANTE, J.S.; ZUCCHI, R.A. Biologia de "moscas-das-frutas" (Diptera: Tephritidae). Lista de hospedeiros e ocorrência. Revista Brasileira de Biologia, v.40, n.1, p.9-16, 1980.

MALAVASI, A.; ZUCCHI, R.A.; SUGAYAMA, R.L. Biogeografia. In: MALAVASI, A.; ZUCCHI, R.A. (Ed.). Moscas-das-frutas de importância econômica no Brasil: conhecimento básico e aplicado. Ribeirão Preto: Holos Editora, 2000. p.93-98.

MORGANTE, J.S. Moscas-das-frutas (Dip.: Tephritidae) Características biológicas, detecção e controle. Brasília: Ministério da Agricultura e Reforma Agrária, 1991. 19p. (Boletim Técnico).

MOURA, A.P.; MOURA, D.C.M. Espécies de moscasdas-frutas (Diptera:Tephritidae) associadas à cultura da goiabeira (Psidium guajava, Linnaeus) em Fortaleza, Ceará. Arquivos do Instituto Biológico, São Paulo, v.73, n.1, p.65-71, 2006.

RAGA, A.; MACHADO, R.A.; SOUSA FILHO, M.F.; SATO, M.E.; SILOTO, R.C. Tephritoidea (Diptera) 
species from Myrtaceas fruits in the State of São Paulo. Entomotropica, v.20, n.1, p.11-14, 2005.

RONCHI-TELLES, B.; SILVA, N.M. Flutuação populacional de espécies de Anastrepha Schiner (Diptera: Tephritidae) na Região de Manaus, AM. Neotropical Entomology, v.34, n.5, p.733-741, 2005.

SALLES, L.A.B. Biotecnologia e controle da mosca das frutas sul americanas. Pelotas: EMBRAPA - CPACT, 1995. 51p.

SALLES, L.A.B. Biologia e ciclo de vida de Anastrepha fraterculus. In: MALAVASI, A.; ZUCCHI, R.A. (Ed.). Moscas-das-frutas de importância econômica no Brasil: conhecimento básico e aplicado. Ribeirão Preto: Holos Editora, 2000. p.81-86.

SALLES, L.A.B. Moscas-das-frutas nos estados brasileiros - Ceará. In: MALAVASI, A.; ZUCCHI, R.A. (Ed.). Moscas-das-frutas de importância econômica no Brasil: conhecimento básico e aplicado. Ribeirão Preto: Holos Editora, 2000. p.217-222.

SANTOS, J.D.; SANTOS, J.H.R.; CARDOSO, E.A.; SOUZA, R.P.; FILGUEIRA, M.A.; CHAVES, J.W.N. Flutuação populacional de moscas-das-frutas do gênero Anastrepha (Diptera:Tephritidae) em goiabeira (Psidium guajava L.) no município de Mossoró-RNBrasil. Caatinga, v.11, n.1/2, p.91-93, 1998.

SILVEIRA NETO, S.; NAKANO, O.; BARDIN, D.; VILA NOVA, N.A. Manual de ecologia dos insetos. São Paulo: Agronômica Ceres, 1976. 420p.

SOUTHWOOD, T.R.E. Ecological methods: with particular reference to the study of insect populations. 2.ed. London: Chapman \& Hall, 1995. 524p.

SOUZA-FILHO, M.F.; RAGA, A.A.; AZEVEDO-FILHO, J.A.; STRIKIS, P.C.; GUIMARÃES, J.A.; ZUCCHI, R.A. Diversity and seasonality of fruit flies (Diptera: Tephritidae and Lonchaeidae) and their parasitoids
(Hymenoptera: Braconidae and Figitidae) in orchards of guava, loquat and peach. Brazilian Journal Biology, v.69, n.1, p.31-40, 2009.

SOUZA FILHO, Z.A.; ARAÚJO, E.L.; GUIMARÃES, J.A.; SILVA, J.G. Endemic parasitoids associated with Anastrepha spp. (Diptera: Tephritidae) infesting guava (Psidium guajava L.) in southern Bahia, Brazil. Florida Entomologist, v.90, p.783-785, 2007.

URAMOTO, K. Biodiversidade de moscas-das-frutas do gênero Anastrepha (Diptera: Tephritidae) no campus Luiz de Queiroz, Piracicaba, São Paulo. 2002. 85p. Dissertação (Mestrado) - Escola Superior de Agricultura "Luiz de Queiroz", Universidade de São Paulo, Piracicaba, 2002.

URAMOTO, K.; WALDER, J.M.M.; ZUCCHI, R.A. Flutuação populacional de moscas-das-frutas do gênero Anastrepha Schiner, 1868 (Diptera, Tephritidae) no Campus "Luiz de Queiroz", Piracicaba, São Paulo. Arquivos do Instituto Biológico, São Paulo, v.70, n.4, p.459465, 2003.

URAMOTO, K.; WALDER, J.M.M.; ZUCCHI, R.A. Biodiversidade de moscas-das-frutas do gênero Anastrepha (Diptera, Tephritidae) no campus da ESALQ-USP, Piracicaba, São Paulo. Revista Brasileira de Entomologia, v.48, n.3, p.409-414, 2004.

VELOSO, V.R.S. Dinâmica populacional de Anastrepha spp. e Ceratitis capitata (Wied., 1824) (Diptera: Tephritidae) nos cerrados de Goiás, Goiânia, GO. 1997. 115p. Tese (Doutorado) - Escola de Agronomia, Universidade Federal de Goiás, Goiânia, 1997.

ZUCCHI, R.A. Taxonomia. In: MALAVASI,A.; ZUCCHI, R.A. (Ed.). Moscas-das-frutas de importância econômica no Brasil: conhecimentos básicos e aplicado. Ribeirão Preto: Holos Editora, 2000. 327p.

Recebido em $17 / 4 / 09$

Aceito em 13/10/09 
